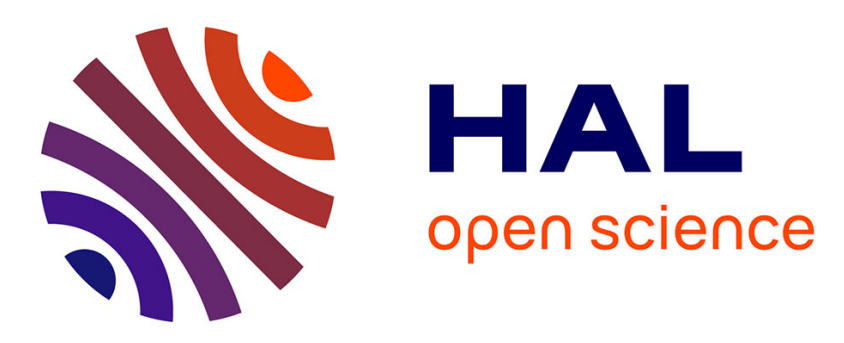

\title{
In-situ X-ray tomographic monitoring of gypsum plaster setting
}

Jérôme Adrien, Sylvain Meille, Solene Tadier, Éric Maire, Layla Sasaki

\section{To cite this version:}

Jérôme Adrien, Sylvain Meille, Solene Tadier, Éric Maire, Layla Sasaki. In-situ X-ray tomographic monitoring of gypsum plaster setting. Cement and Concrete Research, 2016, 82, pp.107-116. 10.1016/j.cemconres.2015.12.011 . hal-01538018

\section{HAL Id: hal-01538018 https://hal.science/hal-01538018}

Submitted on 6 Jun 2019

HAL is a multi-disciplinary open access archive for the deposit and dissemination of scientific research documents, whether they are published or not. The documents may come from teaching and research institutions in France or abroad, or from public or private research centers.
L'archive ouverte pluridisciplinaire HAL, est destinée au dépôt et à la diffusion de documents scientifiques de niveau recherche, publiés ou non, émanant des établissements d'enseignement et de recherche français ou étrangers, des laboratoires publics ou privés. 


\section{In-situ X-Ray tomographic monitoring of plaster setting}

${ }^{1}$ Université de Lyon, INSA-Lyon, MATEIS CNRS UMR5510, Villeurbanne, France

6 * corresponding author. Tel.: +33 4724363 81; fax: + 33472438539 .

$7 \quad$ E-mail address: jerome.adrien@insa-lyon.fr

10 Abstract

12 The first real time monitoring of plaster hydration using X-Ray tomography is reported in this

13 paper. Dissolution of hemihydrate particles and formation of a network of gypsum needles can be 14 observed in 3D. A 3D quantitative analysis based on the microstructure evolution allows the 15 determination of the degree of reaction. In particular, the size of hemihydrate particles is shown to

16 have an influence both on the hydration kinetics and on the final microstructure of the set plaster.

17 This work paves the way to the understanding of the relationship between microstructure evolution, 18 chemical degree of reaction and mechanical strength development for material processed through a 19 setting reaction.

21 Keywords

23 Hydration (A), Kinetics (A), Microstructure (B), Particle size distribution (B), in-situ X-Ray 24 tomography 


\section{Introduction}

28 Plaster is one of the most ancient materials used for construction in the world, with evidence of its

29 use over several thousands of years (traces of gypsum in ancient Egypt are often considered as the

30 first example of its use). Plaster is still largely used for dry wall due to its low cost, low toxicity, low

31 embodied energy and also to its lightweight, sound absorption and fire resistance.

32 Its production starts from the calcination of gypsum, calcium sulfate dihydrate $\left(\mathrm{CaSO}_{4} \cdot 2 \mathrm{H}_{2} \mathrm{O}\right)$, at

33 around $120-130^{\circ} \mathrm{C}$. During calcination calcium sulfate dihydrate loses $3 / 4$ of its crystallization water

34 and turns into calcium sulfate hemihydrate $\left(\mathrm{CaSO}_{4}, 0.5 \mathrm{H}_{2} \mathrm{O}\right)$ also referred to as plaster powder.

35 Plaster is then prepared as a solid binder through a hydration reaction in water, with the dissolution

36 of calcium sulfate hemihydrate $(\mathrm{HH})$ and the precipitation of calcium sulfate dihydrate (DH), as

37 shown in Eq. 1. "Plaster" usually refers to both the calcium sulfate hemihydrate and to the final set

38 material, made of calcium sulfate dihydrate. It can be classified as a hydraulic binder and its

39 hydration is usually considered as being well understood, involving only one chemical reaction and

40 fully crystalline highly pure components.

$$
\mathrm{CaSO}_{4} \frac{1}{2} \mathrm{H}_{2} \mathrm{O}+\frac{3}{2} \mathrm{H}_{2} \mathrm{O} \rightarrow \mathrm{CaSO}_{4} 2 \mathrm{H}_{2} \mathrm{O}
$$

The driving force for this hydration reaction is the higher solubility of $\mathrm{HH}$ in water as compared to DH. This phenomenon has been described first by Lavoisier and Le Chatelier back in 1765 and 1887 respectively and is largely reviewed in the literature. Authors often consider three steps in the hydration of plaster: dissolution of calcium sulfate hemihydrate leading to a

48 supersaturated solution with respect to gypsum, nucleation and growth of gypsum needles and final

49 formation of a solid material by entanglement of gypsum needles with complete depletion of $\mathrm{HH}$.

50 The water to plaster (W/P) ratio, i.e. the amount of water used to hydrate the HH powder, is always 
51 well above the theoretical stoichiometric mass ratio of 0.186 . This higher amount of water increases

52 the fluidity of the paste, which becomes moldable. This also explains the high level of porosity in

53 the final material obtained after complete drying of the excess water.

55 Monitoring and controlling the kinetics of the setting reaction are critical for industrial purposes and 56 many studies can be found in the literature on the use of chemical additives to accelerate or to delay 57 the setting time of plaster. During the setting process, the plaster evolves both from a chemical point 58 of view (monitored by the degree of reaction) and from a mechanical point of view (from a liquid 59 paste to a solid material). Therefore, both aspects have been thoroughly investigated. For instance,

60 the monitoring of the hydration reaction can be carried out using a large number of techniques, the 61 most popular being calorimetry [1] as the hydration reaction (Eq. 1) is exothermic. Additional 62 methods are also used such as electrical conductimetry in diluted pastes [2], X-Ray diffraction [3] 63 or nuclear magnetic resonance [4] to determine the rate of water consumed by the hydration 64 reaction. Other analytical techniques can be used, such as differential thermal analysis or particle 65 size analysis but they can only be implemented ex-situ; thus, they require to stop the reaction at 66 different times, and demand one sample per studied time. Nevertheless, all these methods allow the 67 determination of the degree of the hydration reaction.

68 On the other hand, the solidification of plaster can be monitored by the measurement of rheological 69 and mechanical properties during setting, either with standard methods just like Vicat and Gilmore 70 needles, knife setting time, or using rheometers. The evolution of the elastic modulus versus time 71 can also be monitored by the measurement of ultrasound speed through the setting paste [5].

72 Some authors tried to link the degree of reaction and the development of strength, based on a 73 description of the development of the microstructure at different times. Lewry and Willamson [1] 74 suggested an evolution of the microstructure in three stages: firstly, development of a matrix of 75 gypsum needles providing the initial strength, then relief of internal stresses caused by the built-up 76 of pressure associated with needles growth and finally increase of strength due to water evaporation 
after complete hydration.

78 The detailed description of the bonds formation between gypsum crystals is beyond the scope of our

79 study, but it is admitted that the contact forces are highly dependent on the crystallographic

80 orientation of the crystal faces in contact, as measured by atomic force microscopy [6,7].

81 The morphological description of the entanglement of gypsum crystals after hydration, as well as its

82 structuring during the hydration phase, is critical as it directly controls the final strength of the

83 material. The observation of the evolution of plaster microstructure with time is seldom described in

84 the literature and mainly after having stopped the hydration at different times. The only study where

85 the setting process has been monitored in-situ is, to the best of our knowledge, the work by Ridge

86 [8] showing the growth of gypsum needles under an optical microscope. Lewry and Willamson

87 carried out a post-mortem analysis based on scanning electron micrographies of fractured surfaces

88 after having stopped the hydration at different stages. This allowed them to show the concomitant

89 presence of partly solubilized HH particles and newly formed gypsum crystals [9]. This method is

90 widely used to characterize the local organization of crystals due to its relative easiness and the high

91 resolution one can reach. However, it is not possible to monitor in-situ the evolution of the

92 microstructure during setting. Besides, the protocol used to stop the hydration might impact on the

93 observed microstructure.

94 X-Ray tomography has a strong potential for the study of plaster hydration, the presence of water

95 and solid ensuring a good contrast between the phases. Historically, the first scans of gypsum were

96 acquired at high resolution using synchrotron source on a hydrated plaster [10]. Recent work was

97 done on the in-situ mechanical loading of fully hydrated plaster in a X-Ray tomograph [11]. Only

98 two studies deal with the use of X-Ray tomography during hydration of plaster [4,10]. In Bentz

992002 [10], 3D scans showed the concomitant existence of gypsum crystals and HH particles, but

100 without any quantitative analysis. In Song 2009 [4], 3D scans with a voxel size of $3 \mu \mathrm{m}$ of

101 hydrating plaster were acquired after stopping the hydration reaction after 60 minutes. Pore volume

102 distribution was analyzed but no specific analysis of the pore evolution with hydration time was 
103 performed. One example of an in-situ monitoring of hydration was carried out on a cement paste

104 [12]. The hydration was studied with X-Ray synchrotron tomography from 1 to 60 days, as the 105 hydration kinetics is much slower than for gypsum. The resolution of the X-Ray device used in this study, even if as low as $0.7 \mu \mathrm{m}$, was a limitation to monitor the cement hydration as the calcium silicate hydrates controlling the strength are nanosized.

3D volumes with a voxel size of a few micrometers can be acquired and reconstructed in about 3 minutes on a lab scale apparatus thanks to recent development in microtomography. The present study focuses on the real time monitoring of plaster setting using X-Ray tomography, for the first

112 time to the best of our knowledge. The volume of material studied here is sufficiently large to give 113 an average behavior of the setting of a plaster paste, with a statistical number of $\mathrm{HH}$ particles 114 dissolving and with fluidity typical of an industrial process. 3D quantitative volume analysis is 115 reported and the influence of $\mathrm{HH}$ particle size on the setting process and on the final microstructure of plaster is investigated; the evolution of $\mathrm{HH}$ particle size versus hydration time is also examined.

\section{2. Materials and methods}

\subsection{Plaster preparation}

122 A beta calcium sulfate hemihydrate was used for this study, supplied in store retail, with purity 123 above $96 \%$. The hydration reaction was prepared using a W/P ratio of 0.72 . In general, the powder 124 was used as received. In order to understand the influence of the granulometry of the raw powder on 125 the microstructure of the set plaster, some plaster samples were prepared with $\mathrm{HH}$ sieved powder 126 (either between 63 and $40 \mu \mathrm{m}$ or below $40 \mu \mathrm{m}$ ).

127 The time when the $\mathrm{HH}$ powder was put in contact with water is referred to as the initial time in the 128 paper. $\mathrm{HH}$ and tap water, stored at $23^{\circ} \mathrm{C}$, were mixed by hand for 3 minutes. For X-Ray tomography 
observation, the paste was injected with a syringe into a drinking straw with a diameter of $3 \mathrm{~mm}$,

130 directly mounted on the X-Ray tomograph. Knowing that surfaces of the setting paste were not

131 observed, it was assumed that the bulk of the sample remained saturated with respect to water

132 during the time period required for the complete acquisition ( $1 \mathrm{~h} 44 \mathrm{~min}$ ). Setting time was

133 separately characterized on the remaining paste, which was not injected into the straw, by the knife

134 setting time method: setting time was then defined as the time after which a cut made in the paste 135 with a blade remained opened.

\subsection{X-Ray tomography - in-situ setting of the plaster}

The internal observation of the microstructure evolution during the plaster setting was carried out by means of X-Ray tomography using a vtomex device (GE Phoenix|X-Ray GmbH) equipped with 141 a $160 \mathrm{kV}$ nano-focus tube, a tungsten transmitting target, and a 1920 x 1536 pixel Varian detector -

142 see [13] for more details. The X-Ray tube produces a polychromatic conical beam. The experiments 143 were performed at a voltage of $80 \mathrm{kV}$ and a current of $280 \mu \mathrm{A}$, with a voxel size of $2.5 \mu \mathrm{m}^{3}$. Due to 144 the fast changes during hydration, the acquisition parameters were optimized in order to reduce the 145 scan time. A continuous rotation was used and the integration time was 333 ms for each of the 600 146 projections acquired over $360^{\circ}$. These parameters resulted in measurement periods of $200 \mathrm{~s}$ for a 147 complete scan. The first scan was acquired 13 minutes (800 s) after the initial time; these $800 \mathrm{~s}$ 148 corresponded to the time needed to prepare the sample (600 s) and to perform the first acquisition 149 (200 s). In total, plaster setting was monitored during $6200 \mathrm{~s}$ after the initial time. After this time 150 period, no more modification in the microstructure could be noted. The sample was then dried 151 outside of the tomograph at $45^{\circ} \mathrm{C}$ until constant weight was reached. It was re-scanned afterwards to 152 observe the final set and dried microstructure. Because fast acquisition was no longer an issue, this 153 last scan (denoted $24 \mathrm{~h}$ in the paper) was achieved with improved conditions i.e., 900 projections 154 and averaging of 3 images at each step angle. 
155 For coding the absolute value of the attenuation coefficient of each voxel, 32 bits volumes were

156 reconstructed from the projections. The reconstructed volumes were first subjected to a median

157 filtering. Then, the different scans were spatially registered: each scan was aligned with respect to

158 the previous one to better follow-up the evolution of the microstructure versus time.

160 2.3. X-Ray tomography - final microstructure

162 X-Ray tomography was also used to perform 3D analysis at very high resolution $\left(0.4 \mu m^{3}\right.$ per

163 voxel) of the final microstructure of small pieces of plaster once set ex-situ ( $0.5 \times 0.5 \times 5 \mathrm{~mm})$.

164 Note that such a very small voxel size requires very much care in doing the tomographic 165 acquisition. The tomograph used, different from the one used for the in-situ experiment, was 166 designed by the company RX Solutions. This tomograph is equipped with a $\mathrm{LaB}_{6}$ emission tip for 167 the X-Ray source, which ensures that the actual spot size is physically smaller than $0.4 \mu \mathrm{m}$. The 168 resolution is then not modified by geometric blur and that the voxel size is really close to $0.4 \mu \mathrm{m}^{3}$. 169 The Hammamatsu X-Ray source was operated with a $\mathrm{LaB}_{6}$ cathode at a voltage of $100 \mathrm{kV}$. The 170 detector was a Hamamatsu CCD camera with a pixel size of $12 \mu \mathrm{m}$. Each scan consisted of 900 171 projections with an exposure time of $5 \mathrm{~s}$ and an averaging of 3 radiographs for each projection. The 172 cone-beam XCT data were reconstructed by a filtered back projection Feldkamp-algorithm. The 173 reconstructed data were processed and visualized with the public domain ImageJ / Fiji shareware $174[14,15]$.

175 High resolution tomography was also carried out after final hydration of $\mathrm{HH}$ powder sieved 176 between 63 and $40 \mu \mathrm{m}$ and below $40 \mu \mathrm{m}$ to check for the differences in microstructure with the 177 reference material, prepared from unsieved powder. 


\subsection{D volumes analysis and quantification}

183 A quantitative analysis of the 3D volumes was also carried out. The analyzed volume was $1.5 \mathrm{~mm}^{3}$ 184 i.e., sufficiently large to collect significant information about the setting process as it contained 185 initially tens of thousands of $\mathrm{HH}$ particles larger than $5 \mu \mathrm{m}$. The voxel gray values distribution in this volume was recorded at different times ranging from $800 \mathrm{~s}$ to $6200 \mathrm{~s}$, as well as after the drying of the plaster; the corresponding histograms were computed. In parallel, the absolute value of the attenuation coefficient of the different phases present in the setting material were determined from specific regions using the volumes where they were the most present i.e., on the first volume (acquired at $800 \mathrm{~s}$ ) for $\mathrm{HH}$ particles and ionic solution and on the last volume (6200 s) for gypsum and trapped air.

192 In order to study the influence of the particle size of the HH reactant powder on dissolution kinetics, easy to recognize individual $\mathrm{HH}$ particles of different initial sizes were manually selected and the evolution of their thicknesses was followed with time. Note that HH particles were all connected at the first observation time, which complicated the quantitative image analysis since the morphology of the individual $\mathrm{HH}$ particles could not be measured easily. Therefore, their size was measured using a mathematical morphology operation named "granulometry" (see [16] for more details). Also, about $70 \mathrm{HH}$ particles ranging from below $10 \mu \mathrm{m}$ up to $70 \mu \mathrm{m}$ were manually selected and divided into 7 classes depending on their initial measurable thickness, referred to as $T_{800}$ in this study. For each class, the average thickness over 10 particles was calculated and its evolution with hydration time was plotted.

A 3D rendering of $\mathrm{HH}$ particles in the initial paste and of large porosities after setting was also computed. A first algorithm was used to detect 3D clusters of connected voxels and to label each

204 separate connected clusters. Morphological parameters of these labels were finally calculated 205 (volume, position, ...).

206 Last but not least, granulometry measurement were performed on image acquired at $2.5 \mu^{3}$ to 
207 assess the mesopore distribution. This method was also applied on high resolution images to

208 measure the thicknesses of both gypsum phase and micropores.

209

\section{3. Results}

\section{3.1. In-situ qualitative observation of microstructural evolutions during setting}

214 The evolution of plaster microstructure during setting was first qualitatively observed. Figure 1 215 shows a same tracked cross-section obtained from the reconstructed volumes at five different times 216 and after complete setting and drying of the sample (indicated as $24 \mathrm{~h}$ ). The quality of the 217 reconstruction is obviously not perfect. This is because of the low signal to noise ratio due to the 218 fast acquisition and also to the possible motion of the sample during the time required for a scan.

219 The microstructure of the sample is however rather clearly distinguishable from these images.

220 In the first picture scanned after 800 seconds (corresponding to the very first acquisition after the 221 initial time), $\mathrm{HH}$ rounded particles are clearly visible in white, surrounded by a phase consisting of 222 an ionic solution and gypsum crystals nuclei (in dark gray). The gypsum nuclei could not be imaged 223 at such a resolution. Two large entrapped air bubbles, in black, can also be observed as frequently 224 noted in set plaster [17]. The different morphologies and gray levels observed for the distinct phases 225 (HH, ionic solution, gypsum and air) allowed us to monitor the evolution of each phase separately 226 during the setting of the material. 


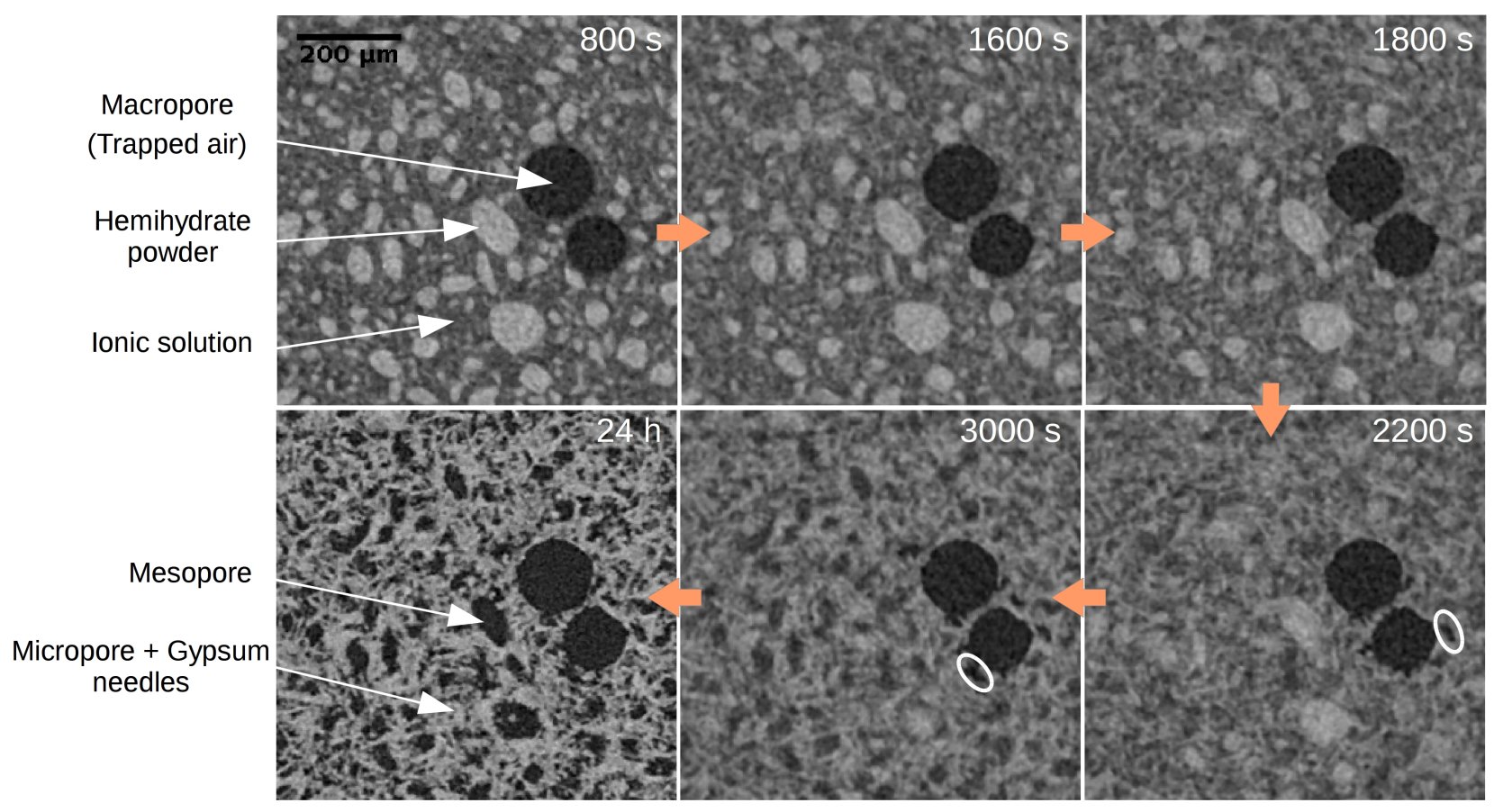

228 Fig. 1. Microstructural changes during the setting of plaster. Reconstructed 2D slices extracted from

229 the 3D volumes acquired during the in-situ tomography experiments, between 800 and 3000 230 seconds. The last slice (24h) was obtained after drying at $45^{\circ} \mathrm{C}$.

233 When considering the images shown in Figure 1 and the corresponding animated sequence 234 (Video_1), modifications in the microstructure with setting time are evident. In particular, two 235 phenomena are observable:

236 - the progressive dissolution of $\mathrm{HH}$ particles, with a visible influence of their size, the largest ones being the last ones to completely disappear,

- $\quad$ the formation of a network of gypsum needles inside the initial dark gray area i.e., inside the

240 Both phenomena occurred in parallel, leading to a decrease of the gray level in the initial HH grain

241 areas and to its increase in the zone initially occupied by the ionic solution. This indicates a clear

242 transport of matter from the HH particles towards the solidifying crystals inside the ionic solution. 
243 The entrapped air bubbles seemed unaffected by the setting reaction, despite a global reduction in

244 size that will be quantified hereafter. One can also note that the desaturation of pores from ionic

245 solution into air could be observed in the tomographic images: at 2200 and 3000 seconds, the pores

246 located close to air bubbles (surrounded by a circle in Figure 1) started to have a darker gray level.

247 As water absorbs X-Ray more than air, its gray value is higher compared to air. Therefore, the

248 darkening of these pores clearly showed that they began to be filled with air rather than water, this

249 phenomenon initiating from entrapped air bubbles.

250 The final microstructure obtained after drying (last image of Figure 1), acquired with the same 251 voxel size but with improved imaging conditions, was typical of set gypsum, with an entanglement 252 of gypsum crystals (in white) and three levels of porosity (in black):

253 - spherical macropores of several hundreds of microns were due to air bubbles entrapped inside 254 the setting paste.

255 - irregularly shaped mesopores of several tens of microns (see arrows in Figure 1) were left by 256 the dissolution of large $\mathrm{HH}$ particles,

257 - micropores formed a percolating network in the space left between entangled gypsum crystals.

258 With these experimental setting conditions, gypsum crystals have a typical average length of $15 \mu \mathrm{m}$ 259 and lateral dimensions between 1 and $2 \mu \mathrm{m}$ [17]; therefore, they could not be individualized with 260 the voxel size used here $\left(2.5 \mu \mathrm{m}^{3}\right)$. The comparison of the first and the final image highlights very 261 clearly that the location of the final mesopores corresponded rather well to the position of initial 262 large HH particles. Excepted for the air bubbles, the final microstructure (24 h) was nearly the exact 263 negative of the initial one (800 s) in terms of attenuation coefficient.

265 Figure 2 shows the 3D rendering of a $\mathrm{HH}$ particle at $800 \mathrm{~s}$ and of the remaining mesoporosity after 266 its complete dissolution. It confirmed that large $\mathrm{HH}$ particles led to the formation of mesoporosities. 267 Morphological measurements were performed from the segmented volumes (cropped around the $268 \mathrm{HH}$ particle and the resulting mesopore) to calculate the respective dimensions of each object. The 
results are summarized in Table 1: the mesopore was smaller and occupied only $52 \%$ of the initial

$270 \mathrm{HH}$ particle volume, with an average uni-dimensional shrinkage of about $18 \%$.

271 The same labeling measurements were performed separately on all trapped air bubbles. The results

272 showed a limited volume decrease of approximately $8 \%$ between the first and the last acquisition

273 and a negligible variation of the inter-bubble distance.

274

275

276

277

278

279

280

281

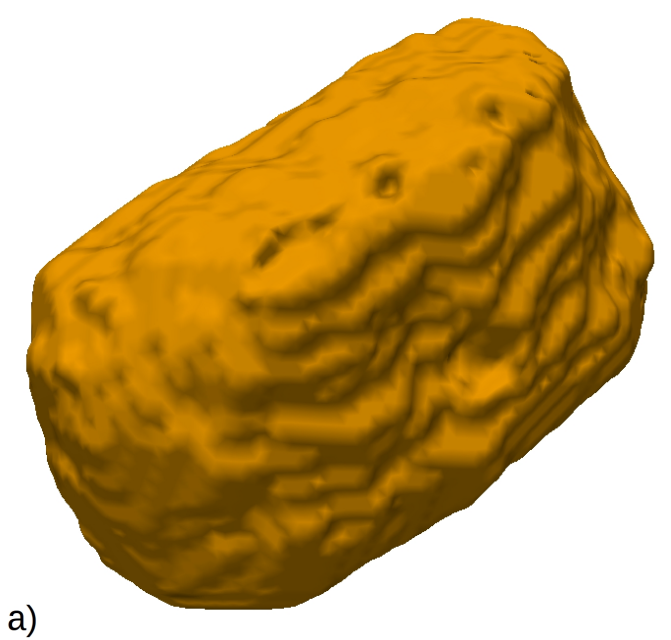

b)

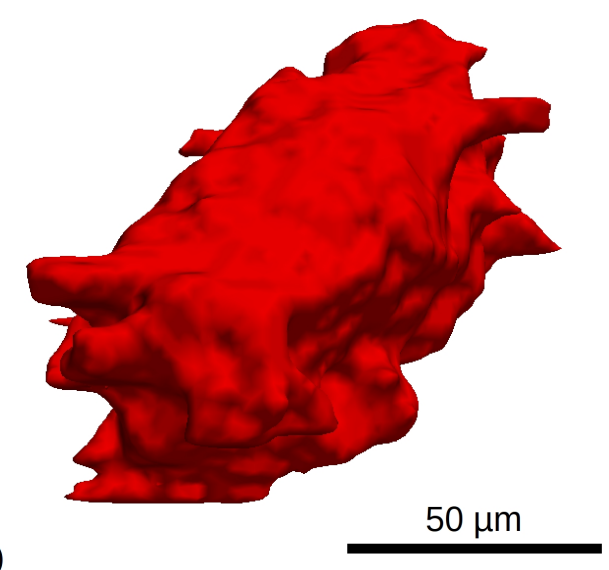

282

283 Fig. 2. 3D rendering of a) $\mathrm{HH}$ particle (800 s), length $=123 \mu \mathrm{m}$ b) Resulting mesopore after setting 284 and drying (24 h), length $=113 \mu \mathrm{m}$.

285

286

\begin{tabular}{ccccc}
\hline & Volume $\left(\mu \mathrm{m}^{3}\right)$ & $\mathrm{A}(\mu \mathrm{m})$ & $\mathrm{B}(\mu \mathrm{m})$ & $\mathrm{C}(\mu \mathrm{m})$ \\
\hline Hemihydrate particle (HH) at 800 s & 566844 & 123 & 74 & 60 \\
Mesopore (P) at 24 h & 296437 & 113 & 55 & 47 \\
P/HH ratio & 0.52 & 0.92 & 0.74 & 0.78
\end{tabular}

Table 1. Morphological parameters of the $\mathrm{HH}$ particle shown in Figure 2a and of the resulting mesoporosity (Figure 2b). A, B and C are the dimensions of the 3D objects in their three principal axes. 


\subsection{In-situ quantitative analysis of dissolution / precipitation kinetics}

3.2.1. Global analysis - "microstructural” degree of reaction

298 As observed in Figure 1, the distinct phases (HH, ionic solution, gypsum and air) showed different 299 gray levels. Therefore, in addition to a phenomenological description of the microstructure evolution during hydration, a quantitative analysis was carried out using 3D volume analysis. The characteristic gray level of each phase was determined: a typical gray value of 0.05 corresponded to trapped air (macropores), 0.15 to the ionic solution at $800 \mathrm{~s}, 0.21$ to the matrix of growing gypsum crystals surrounded by the ionic solution and 0.31 to initial $\mathrm{HH}$ particles. The histogram of the voxel gray values distribution of the whole volume was computed at different times (Figure 3). At the beginning of the setting reaction, two peaks could be noted, corresponding to ionic water solution and to HH particles. During setting, these two peaks merged into a single one, which arose from the contribution of both the ionic solution and the growing gypsum crystals. The separation of these two phases could not be achieved because of the limited spatial resolution and of the small difference between the gray values of gypsum crystals and of the ionic solution. The gray value of the gypsum peak tended to increase during the setting process. After drying, this single peak separated into two peaks: one for gypsum, and one for air. Please note that imaging conditions were improved for the $24 \mathrm{~h}$ scan (dried plaster).

313 A degree of setting reaction was computed from the evolution of the intensity of the two peaks

314 highlighted by dashed lines in Figure 3 i.e., the HH peak on the one hand and the gypsum peak on 315 the other hand (Figure 4). Due to the setting reaction (Eq. 1), the intensity of the peak corresponding 316 to HH decreased with time while the intensity of the gypsum peak increased. The evolution rate was 317 not constant: after a slow evolution until $1000 \mathrm{~s}$, the rate increased up to around $1600 \mathrm{~s}$ for $\mathrm{HH}$ 318 dissolution and around $1800 \mathrm{~s}$ for $\mathrm{DH}$ precipitation. After $2500 \mathrm{~s}$, no significant variations were 319 observed anymore. 


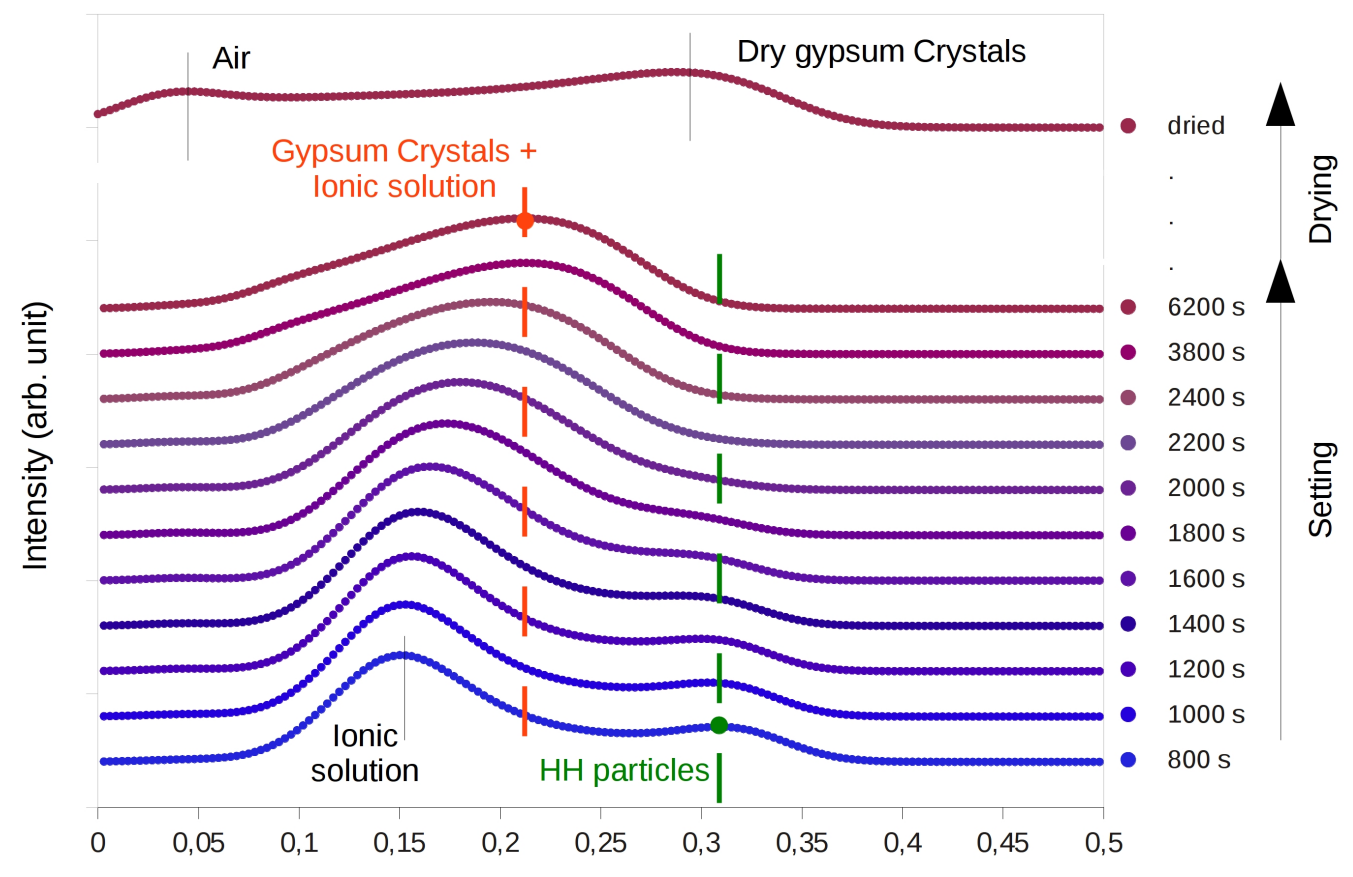

333 Fig. 3. Histograms of the gray values measured in the volumes for different times during setting and

334 then subsequent drying at $45^{\circ} \mathrm{C}$.

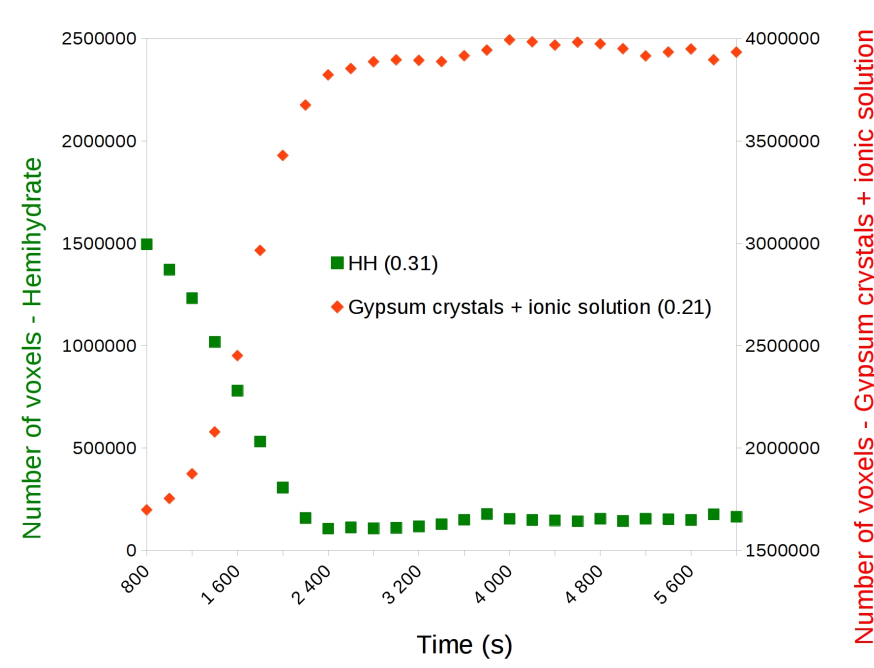

344 Fig. 4. Evolution of the intensity of the HH peak (dashed line in Figure 3, gray level value $=0.31$ )

345 and of the gypsum peak (dashed line in Figure 3, gray level value $=0.21$ ). 
348 As shown in Figure 1, the particle size of initial HH particles influenced their dissolution kinetics.

349 To quantify this further, two single HH particles of different sizes were chosen and their dissolution

350 was studied, by monitoring the evolution of the gray level profiles across the thickness of the 351 particles with hydration time.

352 Figure 5 presents the evolution of the gray profile for a small $\mathrm{HH}$ particle, $20 \mu \mathrm{m}$ thick, together 353 with the corresponding micro-tomographies. At $800 \mathrm{~s}$, the gray profile highlights the presence of a $354 \mathrm{HH}$ particle located between 11 and $38 \mu \mathrm{m}$ (gray value above 0.3 typical of the HH phase, as shown 355 previously), surrounded by the ionic solution, of characteristic gray values comprised between 0.15 356 and 0.18. For short times, nearly no evolution of this profile could be detected. Then the particle 357 completely dissolved within a few minutes, between 1600 and 3200 s, leading to a mesoporosity 358 filled with ionic solution (gray value around or below 0.1 ) surrounded by a shell made of gypsum 359 crystals and microporosity, again filled with ionic solution. The profiles clearly showed, as already 360 seen in Figure 1, that solid matter was progressively transported from the $\mathrm{HH}$ particle to the 361 surrounding ionic solution where gypsum crystalline needles nucleated and grew, as confirmed by 362 the increase of the gray level in the immediate vicinity of the initial HH particle. 

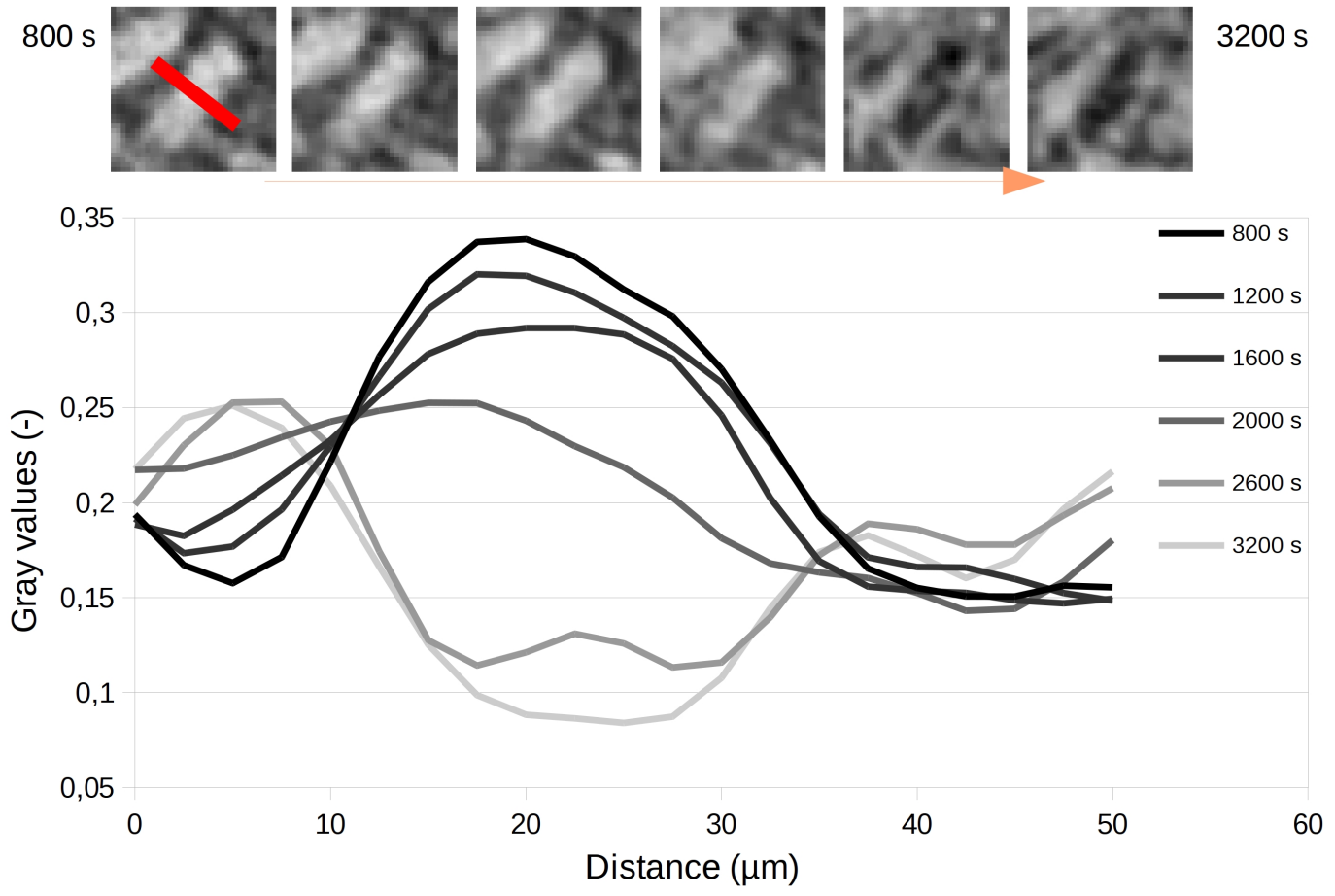

384 Fig. 5. Gray values profile along the red line taken at different setting times. The measurement was focused on a small $\mathrm{HH}$ particle (20 $\mu$ m thick).

An example of the same analysis carried out on a large $\mathrm{HH}$ particle (approximately $70 \mu \mathrm{m}$ thick), is

illustrated in Figure 6. No evolution in the size of the particle was noted before the starting of dissolution at $1600 \mathrm{~s}$. The dissolution suddenly started, occurring first at the surface of the particle. Again, the gray value of the area surrounding the $\mathrm{HH}$ particle increased during the dissolution of the particle: $\mathrm{HH}$ dissolved and matter was transported from the initial particle into the surrounding matrix where entangled needles of gypsum nucleated and grew. One can however note the existence of a shell of around 5 to $7 \mu \mathrm{m}$ around the $\mathrm{HH}$ particle, where the gray value remained at 0.13 all along the dissolution, indicating that the $\mathrm{HH}$ particle was surrounded by a shell of ionic solution through which the matter had to diffuse towards the outside growing crystals. After complete dissolution, a remaining mesopore filled with ionic solution was left where the initial HH particle 
was present. An outer shell made of a network of gypsum crystals and microporosity filled with

399 ionic solution was observed. Figures 5 and 6 show that the behaviors of both small and large $\mathrm{HH}$

400 particles were very similar, excepted for the notable influence of the particle size on the dissolution

401 kinetics. For the smallest $\mathrm{HH}$ particles present in the paste (below $20 \mu \mathrm{m}$ in thickness), this

402 phenomenon was probably too quick to be observed at our temporal resolution.

403

404

405

406

407

408

409

410

411

412

413

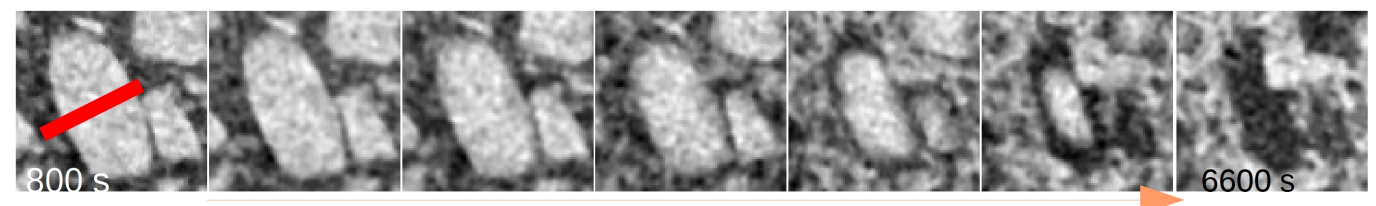

0,4

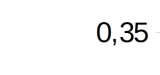

414

415 Fig. 6. Gray values profile along the red line taken at different setting times. The measurement was

416 focused on a large $\mathrm{HH}$ particle (70 $\mu \mathrm{m}$ thick).

418 The evolution within time of the mean thickness of 70 different $\mathrm{HH}$ particles is presented in Figure

$4197 \mathrm{a}$ and confirms statistically the two individual cases discussed above. Even if, at $800 \mathrm{~s}$, the

420 dissolution had apparently already started for $\mathrm{HH}$ particles of size $20 \mu \mathrm{m}$ and below, for most of the

421 largest particles, dissolution had not yet started. Except for the smallest particles, an incubation time

$422 t_{d}$ could indeed be defined (intersection of the two tangent lines, see Figure 7a), during which the 423 particle thickness remained rather constant. This time was computed for each size class of $\mathrm{HH}$ 
424 particles and it was shown that $t_{d}$ slightly increased with size, except for the largest HH particles, for

425 which it was equal to $1820 \mathrm{~s}$ (Table 2). After $t_{d}$, the dissolution speed started to increase, slowly

426 first, then reached a constant rate (steady state of dissolution) and finally decreased again just before

427 the particles were fully dissolved. The linear part of the curve shown in Figure 7a could be used to

428 compute the dissolution speed expressed as the change of the half-thickness versus time (dT/2dt).

429 The calculated dissolution rates are collected in Table 2. For all particles above $50 \mu \mathrm{m}$, rates were

430 all around $1.5 \mu \mathrm{m} \cdot \mathrm{min}^{-1}$. For $\mathrm{HH}$ particles of thicknesses below $40 \mu \mathrm{m}$, the dissolution speed

431 decreased slightly with size. Note that this parameter was not calculated for the smallest particles

432 (below $10 \mu \mathrm{m}$ ) because their dissolution had obviously started earlier than $800 \mathrm{~s}$.

433
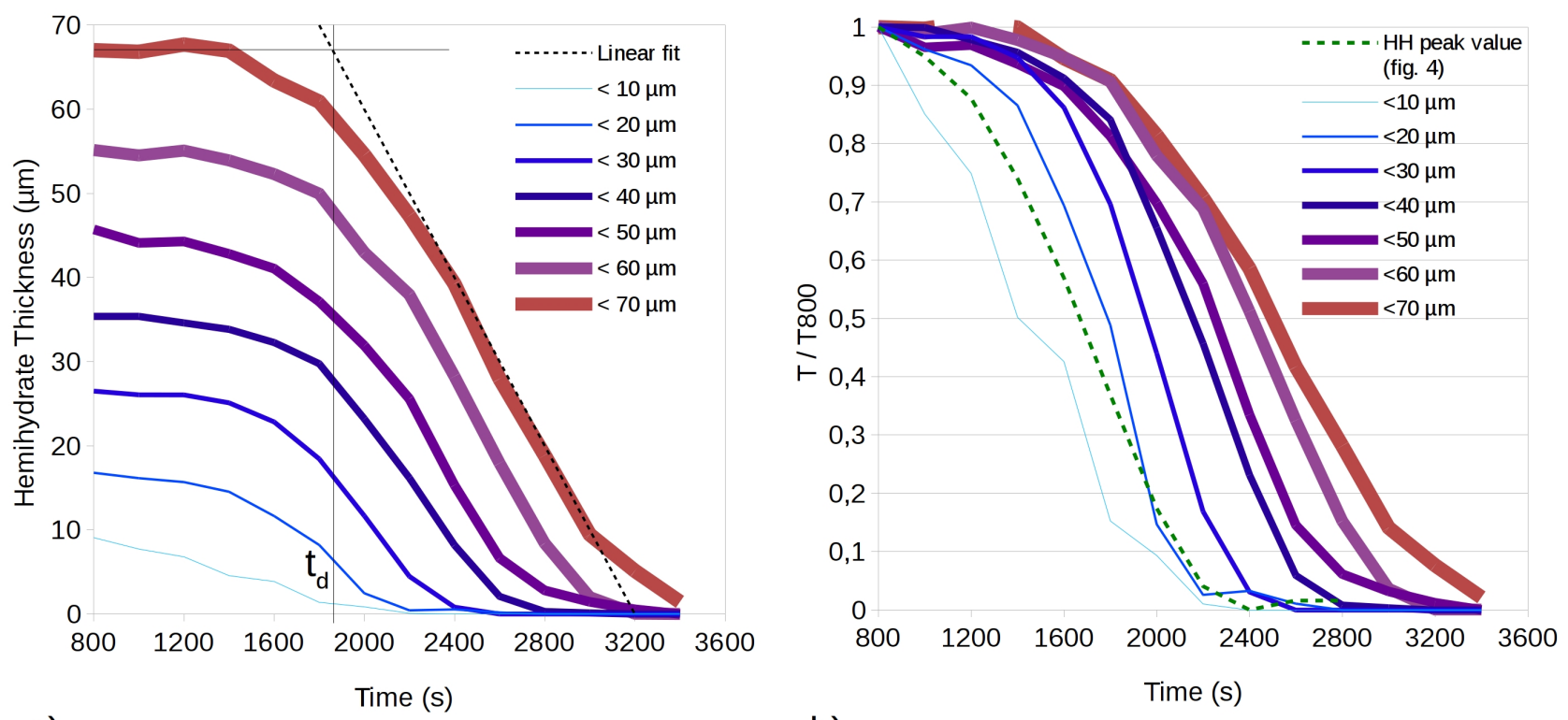

a)

b)

435 Fig. 7. a) $\mathrm{HH}$ thickness evolution during setting for different classes of initial particle sizes b)

436 Normalized thickness evolution of $\mathrm{HH}$ particles (solid lines). The dashed line corresponds to the 437 average $\mathrm{HH}$ dissolution throughout the whole volume as measured from data of Figure 4 (evolution 438 of normalized intensity of $\mathrm{HH}$ gray value peak). 


\begin{tabular}{lcccccc}
\hline Initial HH particles thickness $(\mu \mathrm{m})$ & $<20$ & $<30$ & $<40$ & $<50$ & $<60$ & $<70$ \\
$d T / 2 d t$ in the steady state $\left(\mu \mathrm{m} \cdot \mathrm{min}^{-1}\right)$ & 0.84 & 1.08 & 1.14 & 1.44 & 1.5 & 1.5 \\
Incubation time $t_{d}$ (seconds) & 1500 & 1600 & 1690 & 1780 & 1820 & 1820 \\
\hline
\end{tabular}

443 Table 2. Dissolution speed of the HH particles in the steady state regime (linear fit from Figure 7a) 444 and incubation time $t_{d}$ for the different granulometric classes.

To be able to compare the dissolution kinetics of HH particles of different initial thicknesses, the dissolution curves plotted in Figure 7 were normalized: Figure $7 \mathrm{~b}$ illustrates the evolution of $T / T_{800}$ - thickness of the $\mathrm{HH}$ particle at a given time (denoted $T$ ) to its value at $800 \mathrm{~s}$ (denoted $T_{800}$ ) - for the different $\mathrm{HH}$ particle sizes. Also, the global $\mathrm{HH}$ dissolution curve shown in Figure 4 is reported in dashed line for comparison. It is close to the evolution of $\mathrm{HH}$ particles below $20 \mu \mathrm{m}$.

3.3. Quantitative observation of final microstructure - influence of $\mathrm{HH}$ particles granulometry

Set plasters obtained from the unsieved reference powder, and from $\mathrm{HH}$ powder sieved through two different mesh sizes ( $40 \mu \mathrm{m}<\mathrm{HH}$ particles $<63 \mu \mathrm{m}$ and $\mathrm{HH}$ particles $<40 \mu \mathrm{m}$ ), were characterized after complete setting and drying. Slices of two reconstructed volumes with a voxel size of $2.5 \mu \mathrm{m}^{3}$ are presented in Figure 8a and b. Mesopores observed in the set plaster obtained after sieving of the $\mathrm{HH}$ powder below $40 \mu \mathrm{m}$ (Figure 8b) were significantly smaller than mesopores of the reference material (Figure 8a). Besides, the global observation of the set material seems to reveal that the plaster obtained from the sieved $\mathrm{HH}$ powder was more homogeneous as compared to the reference plaster. We also noted the presence of a larger volume fraction of impurities (in white) in the sieved powder, the volume fraction of which was possibly increased during sieving. 


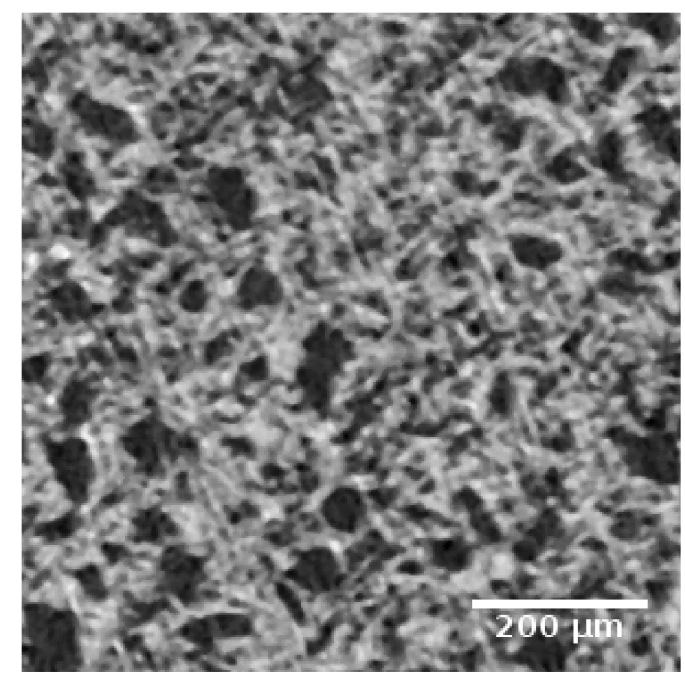

a)

474

475

476

477

478

479

480

481

482

483

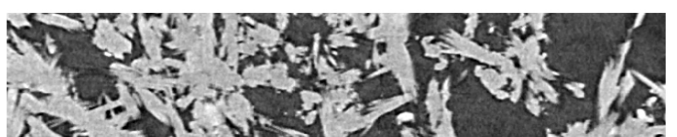

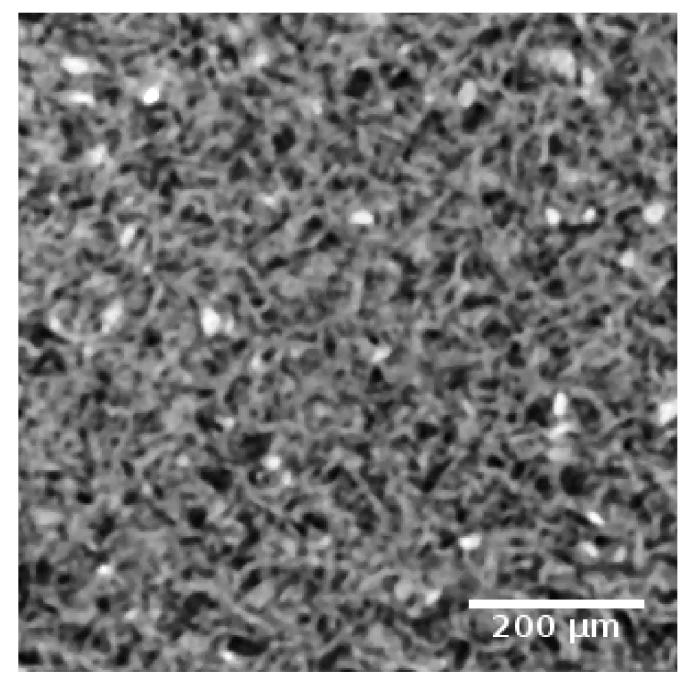

b)

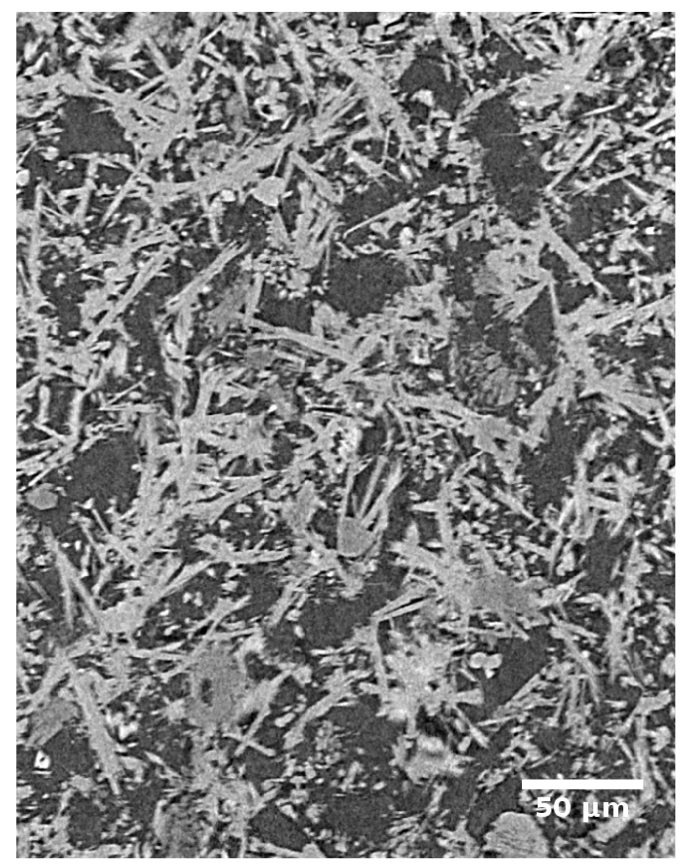

d)

484 Fig. 8. Reconstructed 2D slices extracted from 3D volumes of set plaster samples obtained with a)

485 the as-received $\mathrm{HH}$ powder and b) $\mathrm{HH}$ powder sieved below $40 \mu \mathrm{m}$ - voxel size of $2.5 \mu^{3}$ and set

486 plasters samples prepared with c) as-received powder and d) powder sieved below $40 \mu \mathrm{m}$ - voxel 487 size of $0.4 \mu \mathrm{m}^{3}$.

488

489 To better observe the influence of sieving the initial powder at a smaller scale, the microstructures

490 of both set plasters shown in Figure $8 \mathrm{a}$ and $\mathrm{b}$ were also observed at a resolution of $0.4 \mu \mathrm{m}^{3}$ per

491 voxel (Figure 8c and d). This confirmed the critical role of the large HH particles on the formation 
492 of mesopores in the final material. For the sieved particles, the resulting gypsum network was more

493 homogeneous, with numerous individual crystals and thinner bundles of crystals than in the 494 reference plaster.

495 For quantification purposes, Figure 9 shows the mesopore size measured using the aforementioned 496 granulometry technique from the tomographic scans of set plasters acquired with a voxel size of $4972.5 \mu \mathrm{m}^{3}$ on volumes of $(1.25 \mathrm{~mm})^{3}$. Note that trapped air bubbles were easily excluded from the 498 porosity analysis thanks to their much larger size (diameter $>80 \mu \mathrm{m}$ ) and spherical shape.

499 The results obtained confirmed the influence of the initial $\mathrm{HH}$ particle size on the mesoporosity 500 size: the smaller the initial $\mathrm{HH}$ particles, the smaller the resulting mesopores. When HH particles 501 below $63 \mu \mathrm{m}$ were used, no mesopores larger than $50 \mu \mathrm{m}$ were found and when $\mathrm{HH}$ particles below $50240 \mu \mathrm{m}$ were used, no mesopores larger than $40 \mu \mathrm{m}$ were detected.

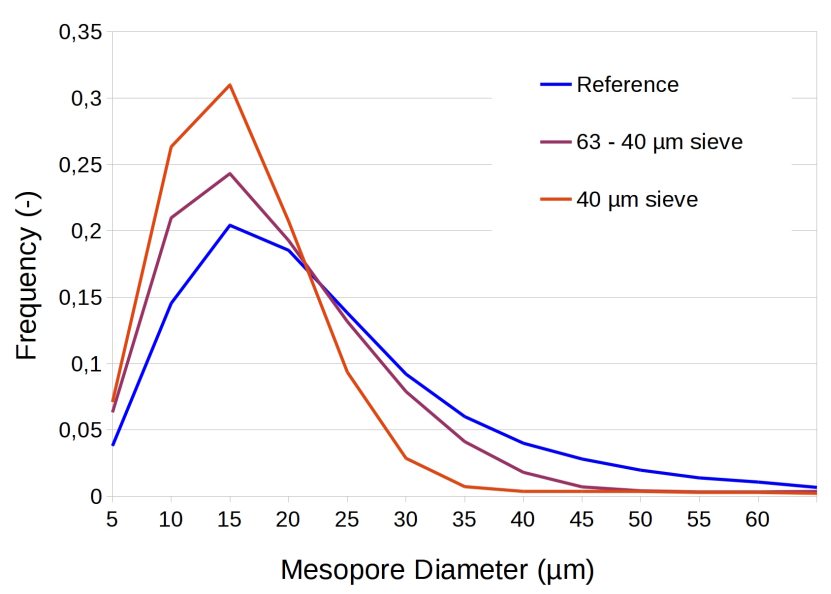

512 Fig. 9. Size distribution of mesopores in set plaster for different HH granulometry. « Reference » for sample prepared with as-received HH powder, « < $40 \mu \mathrm{m}$ » for HH sieved below $40 \mu \mathrm{m}$.

516 Quantitative analysis of the granulometry of both solid and porous phases (including microporosity 517 and mesoporosity) was also carried out on the tomographic scans of set plasters acquired at high 
518 resolution (voxel size of $0.4 \mu \mathrm{m}^{3}$ ). Results are displayed in Figure 10. Data confirmed the finest

519 microstructure generated by the sieved powder: interestingly, when the $\mathrm{HH}$ particles were sieved,

520 not only the pore size was smaller but the gypsum crystals were also thinner and/or more

521 individualized (as already shown in Figure 8).

522

523

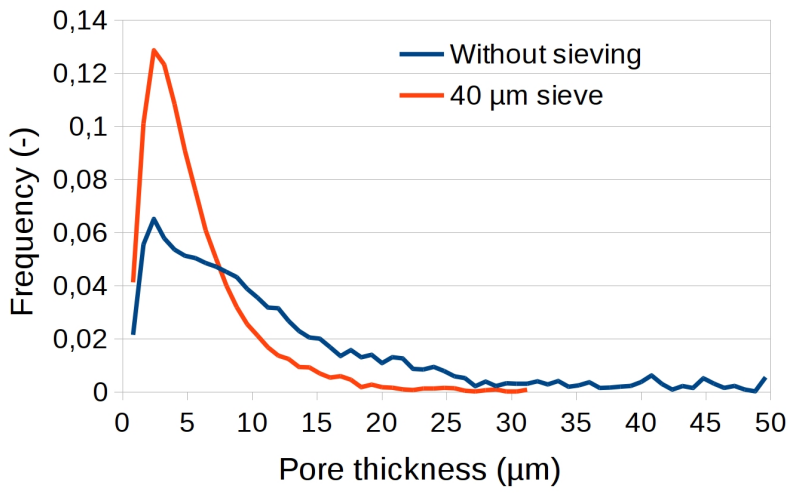

a)

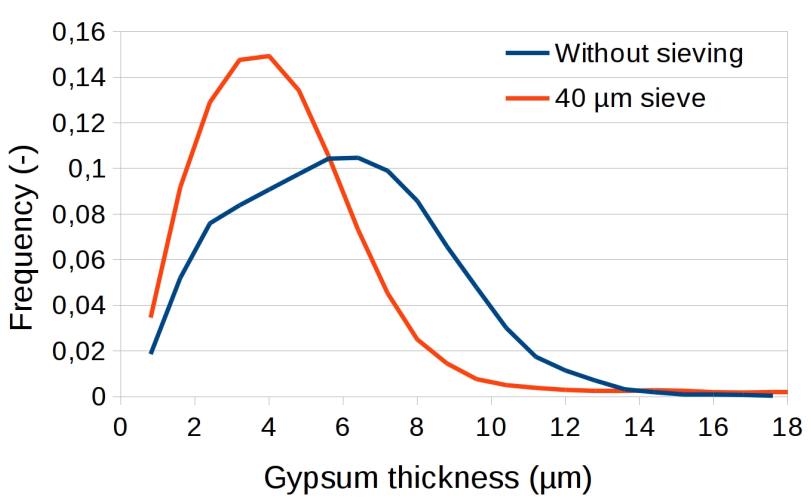

b)

Fig. 10. Granulometry of the porous « phase » (a) and of the gypsum phase (b) measured from high resolution acquisitions $\left(0.4 \mu \mathrm{m}^{3}\right.$ voxel size).

526 The relative density of both set materials could be estimated by a simple count of the white pixels after image thresholding of the high resolution images. The relative density for the reference material was found to be 0.46 compared to 0.51 for the one obtained from the powder sieved below $40 \mu \mathrm{m}$, with an analyzed volume of $300 \times 300 \times 300 \mu \mathrm{m}^{3}$. As the W/P ratio was the same for the two materials, the final density should be exactly the same. The small difference noted could be due to an increase of impurities after sieving or by a more difficult control of the preparation of the sieved material, due to the limited amount of powder and to the higher surface to volume ratio of the sample, favoring water evaporation. 


\section{Discussion}

538 The in-situ X-Ray tomographic observations during plaster setting and the quantitative analysis

539 performed on the reconstructed volumes produced substantial information on the hydration process

540 and on the resulting microstructure.

541 Figure 11 shows a schematic representation of the microstructural changes observed in Video 1

542 during plaster setting, starting from $800 \mathrm{~s}$ after the contact of HH powder with water (Figure 11a).

543 No gypsum nuclei could be observed at this stage due to the limitation in spatial resolution.

544 However, based on the results presented here, it can be assumed that some gypsum crystals were

545 already formed. The dissolution of $\mathrm{HH}$, beginning with the dissolution of the smallest $\mathrm{HH}$ particles,

546 and the growth of dihydrate inside the surrounding ionic solution occurred simultaneously (Figure

547 11b). The formation of a network of gypsum needles was gradually observed (Figure 11c) while

548 locally some large HH undissolved particles were still present confirming the observation by [9]

549 and [10]. Although the limited resolution of the scanned volumes during hydration does not allow a

550 direct observation of nucleation and growth of the gypsum crystals, it was clearly observed that

551 gypsum crystals did not form at the surface of the initially large $\mathrm{HH}$ particles, and that an ionic shell

552 permitting the transport of matter from the dissolving $\mathrm{HH}$ particles towards the growing crystals

553 existed (Figure 11c). The observations showed that the dissolution process was not yet completed

554 after $3000 \mathrm{~s}$ and that part of initially large $\mathrm{HH}$ particles still remained (Figure 11c). After setting,

555 gypsum crystals were not observed where large HH particles were originally located (Figure 11d).

556 The resulting mesopores had nevertheless a smallest size compared to the HH particles at $800 \mathrm{~s}$

557 (52\% of the initial volume), due to gypsum precipitation in the outlying areas. This is clearly shown

558 by the evolution of the gray values around $\mathrm{HH}$ particles between initial and final times in Figures 5 559 and 6.

560 It has also been noted that some mesopores located close to entrapped air bubbles began to be filled

561 with air rather than ionic solution at the last step of hydration (starting from $2200 \mathrm{~s}$ in Figure 1). 
562 This phenomenon probably arose from the consumption of water during the hydration equation of

$563 \mathrm{HH}$ particles (Eq. 1) inducing a desaturation of large pores. It is commonly encountered in Portland

564 cement pastes and associated to an important shrinkage due to the very small pore size of this

565 materials (few nanometers). In our study, the global volume variation of the plaster during setting, measured via the distance between air bubbles, was negligible. The hydration reaction of gypsum is accompanied with a $10 \%$ volumetric shrinkage (usually referred to as Le Chatelier contraction), often counterbalanced by an expansion during gypsum crystal growth [18] as it seems to be the case in our study.

A decrease by $8 \%$ of the total volume of entrapped air was observed between the first and the last volume acquired. Since the inter-bubble distance did not change during hydration, this could be linked to the formation of gypsum crystals on the edges of trapped air bubble (Figure 11d).

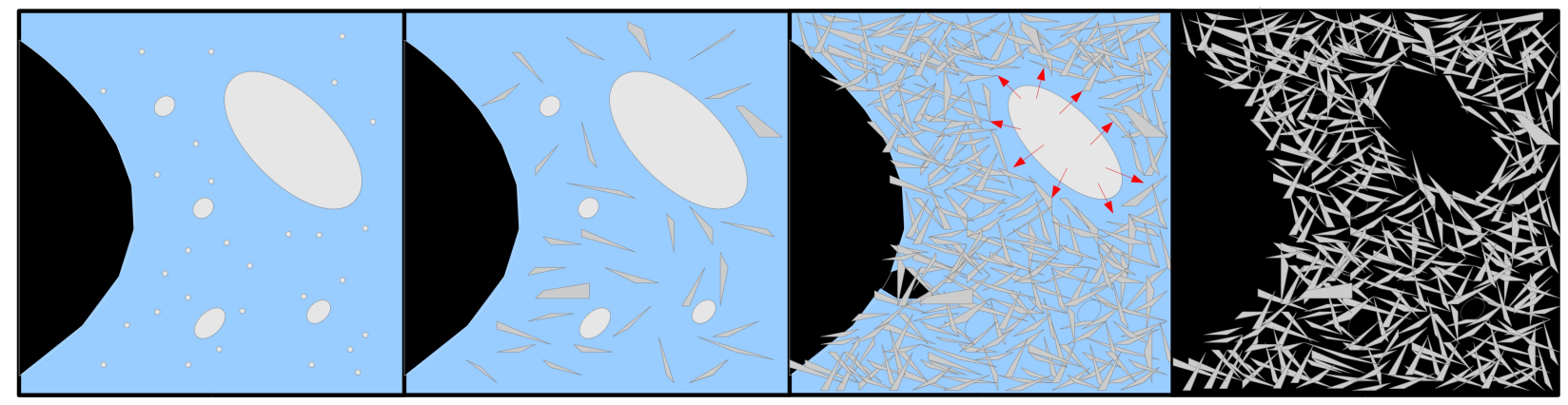

Fig. 11. Schematic representation of the hydration process as monitored by X-Ray tomographic observation (blue : water; black : entrapped air ; white : HH particles of typical size between a few $\mu \mathrm{m}$ and tens of $\mu \mathrm{m}$; gray : DH crystals).

577 Quantitative analysis on the whole volume permitted to compute histograms of the gray values measured at different times (Figure 3). A logical decrease of peaks associated to $\mathrm{HH}$ particles and ionic solution was observed throughout the setting process (Eq. 1). A concomitant increase of the peak associated to DH crystals was noted. During setting, this peak shifted towards higher gray 
581 values due to gypsum precipitation and densification of the solid matrix. After drying, it showed an

582 even stronger shift towards high values. The precipitation of gypsum during evaporation of the 583 remaining water cannot explain such a strong shift. Indeed, a rapid calculation shows that, for the

584 W/P ratio used here, the precipitation of crystals from the remaining ions would lead to a maximum

5851 wt. \%o increase of gypsum. Nevertheless, this last scan has been acquired in different conditions 586 than the previous ones. In particular, the presence of water inside the paste during in-situ 587 observations is known to have a potential detrimental effect on the images contrast (because of X588 Ray beam scattering).

589 The microstructural degree of reaction highlighted two distinct regimes (Figure 4). Starting from $590800 \mathrm{~s}$, there was an acceleration followed by a slowing down of $\mathrm{HH}$ dissolution and $\mathrm{DH}$ 591 precipitation until no more significant changes could be monitored. The times at maximum rates 592 were slightly different for the two phenomena: DH precipitation was logically delayed compared to 593 HH dissolution.

594 Regarding the influence of $\mathrm{HH}$ particle size, at $800 \mathrm{~s}$, the smallest particles had already begun to 595 dissolve whereas large particles seemed unaffected (Figure 7). It seems logical that the incubation 596 time $t_{d}$ increased with the HH particle thickness (Table 2), as smaller particles are more unstable due 597 to their higher surface to volume ratio. Interestingly, the particle size had also an effect on the 598 dissolution rate, which increased with $\mathrm{HH}$ initial thickness (Table 2).

599 Comparing the $\mathrm{HH}$ dissolution curve derived from gray value measurements throughout the volume 600 (Figure 4) with the curves obtained for different ranges of particle sizes showed that the kinetics 601 measured globally was close to that observed for small particles (Figure $7 \mathrm{~b}$ ). This can be explained 602 by the large amount of small particles found in the initial powder, which could not be imaged due to 603 the spatial resolution of the tomograph used in this study. It seemed indeed that very few particles 604 of diameter below $20 \mu \mathrm{m}$ had begun to dissolve at $1200 \mathrm{~s}$ (Figure 7), as confirmed by the incubation 605 times (Table 2). However, the knife setting time of this plaster was equal to $1200 \mathrm{~s}$. This time is 606 known to correspond to the percolation of the gypsum phase in the microstructure, meaning that the 
small $\mathrm{HH}$ particles (below $20 \mu \mathrm{m}$ ) controlled the initial strengthening of the paste. This first stage

608 could unfortunately not thoroughly be studied in these experimental conditions. Nevertheless, this

609 study shows that the microstructuration of plaster is far from being completed when the knife setting time is reached and that bigger $\mathrm{HH}$ particles also play a key role in this evolution.

611 The granulometry of $\mathrm{HH}$ powder had indeed a direct influence on the kinetics of dissolution and

612 precipitation but also on the pore size observed after setting. The comparison of set gypsum

613 prepared from as-received $\mathrm{HH}$ powder and $\mathrm{HH}$ powder sieved either between 63 and $40 \mu \mathrm{m}$ or

614 below $40 \mu \mathrm{m}$ clearly confirmed the strong correlation between $\mathrm{HH}$ particles size distribution and mesopore size distribution (Figure 9). This could lead to a possible control of mesopore sizes in the set material. Although the relative density measured for the reference material and for the one obtained after powder sieving was approximately the same, the microstructure of dried plaster obtained with sieved powder was more homogeneous (Figure 8), due to both the decrease of the mesopores size and to the crystallization of thinner or/and better individualized gypsum crystals. Indeed, the gypsum crystals size distribution was wider when as-received $\mathrm{HH}$ particles were used

621 (Figure 10b). Such a behavior may be explained by the difference in dissolution times depending on 622 the size of $\mathrm{HH}$ powder as emphasized in this work. For a narrow size distribution of small $\mathrm{HH}$ 623 particle, the dissolution and subsequent precipitation of gypsum crystals probably occurred over a 624 limited time range, leading to a network of random individualized crystals. For a wide HH size 625 distribution, the dissolution of the smallest particles led to the formation of an initial network of 626 gypsum (controlling the knife setting time). Then, the dissolution of the largest particles released 627 more calcium and sulfate ions leading to additional precipitation of gypsum crystals upon the 628 existing network, as monitored by the in-situ observation of the setting. To the best of our 629 knowledge, it is the first time that a study reports and quantifies that the control of the reactant 630 powder size distribution could permit to regulate the thickness and the agglomeration state of the 631 growing gypsum crystals. This appears therefore to be an interesting way of tuning the final 632 mechanical properties of the set plaster [19]. 
633 It cannot not be completely ensured that the X-Ray beam had no influence on the setting kinetics of

634 plaster. Nevertheless, the impact on the setting process is likely to be negligible. Thermal effects for

635 example, are probably very small compared to the exothermicity of the setting reaction.

636 Also, additional work is required to know if, to get an homogeneous microstructure, the 637 determining characteristics of the $\mathrm{HH}$ reactive powder is the mean particle size, the width of the 638 particle size distribution, or both.

639 The results presented in this paper could feed analytical or numerical models of plaster hydration

$640[10,20,21]$, even if single gypsum crystals could not be individualized due to the resolution used 641 here.

642 X-Ray computed tomography is becoming a very powerful technique to monitor the 643 microstructuration of setting materials but this type of measurements requires high resolution and 644 low noise images. Both a higher spatial resolution and a quicker acquisition would permit to get 645 more insights into the setting process and especially into the first stages of the process. Fast X-Ray 646 computed tomography experiments could be done using synchrotron, which, owing to the high flux 647 of high-energy X-Ray available, would enable a complete high resolution $(1 \mu \mathrm{m})$ tomography 648 acquisition to be performed within a few seconds, instead of several minutes.

\section{Conclusions}

653 The real time imaging of the plaster setting was carried out for the first time, with a paste rheology 654 close to an industrial one.

655 The observation of both the dissolution of $\mathrm{HH}$ and the formation of a network of gypsum crystals 656 was possible. A critical role played by $\mathrm{HH}$ particle size was evidenced: small $\mathrm{HH}$ particles were 657 rapidly dissolved, whereas large particles were still not completely dissolved long after the material 658 had started to set. It was also shown that the final dissolution of the largest particles led to the 
659 formation of mesopores in the hydrated material. To our knowledge, this is the first time that the

660 origin of the presence of such mesopores in set plaster is provided, thanks to in-situ experiments.

661 3D image analysis was performed to obtain quantitative information both on a local scale (selected

662 particles) and on a global scale (whole volume). A local dissolution front speed ranging from

$6631.5 \mu \mathrm{m} / \mathrm{min}$ for large particles to $0.8 \mu \mathrm{m} / \mathrm{min}$ for small ones and a degree of setting reaction based

664 on microstructural evolution were computed. These data could be used in a future study for

665 comparison with the chemical degree of reaction and the development of strength during setting.

666 Another clear outcome of this study is the evidence of the possibility to play on the morphology of

667 the set material by the granulometry of the starting powder, in order to target better mechanical

668 properties at a similar porosity.

669

670

671

672

673

674

675

676

677

678

679

680

681

682

683

684 


\section{References}

687 [1] A.J. Lewry, J. Williamson, The Setting of Gypsum Plaster: Part I The Hydration of Calcium 688 Sulphate Hemihydrate, J. Mater. Sci. 29 (1994) 5279-5284.

689 [2] L. Amathieu, R. Boistelle, Crystallization kinetics of gypsum from dense suspension of 690 hemihydrate in water, J. Cryst. Growth. 88 (1998) 183-192.

691 [3] C. Solberg, S. Hansen, Dissolution of CaSO4 center dot 1/2H(2)O and precipitation of CaSO4 692 center dot 2H(2)O - A kinetic study by synchrotron X-ray powder diffraction, Cement Concrete 693 Res. 31 (2001) 641-646.

694 [4] K.M. Song, J. Mitchell, et al., Magnetic resonance studies of hydration kinetics and 695 microstructural evolution in plaster pastes, J. Mater. Sci. 44 (2009) 5004-5012.

696 [5] Q.L. Yu, H.J.H Brouwers, A.C.J. Korte, Gypsum Hydration: a Theoritical and Experimental 697 Study, In: 17th International Conference on Building Materials, ibausil, Weimar, Germany; 2009.

698 [6] E. Finot, E. Lesniewska, et al., Investigations of surface forces between gypsum crystals in 699 electrolytic solutions using microcantilevers, J. Chem. Phys. 111 (1999) 6590-6598.

700 [7] E. Finot, E. Lesniewska, et al., Correlating surface forces with surface reactivity of gypsum 701 crystals by atomic force microscopy. Comparison with theological properties of plaster, Solid State 702 Ionics 141 (2001) 39-46.

703 [8] M.J. Ridge, Crystal growth in gypsum plaster setting, Aust. J. Appl. Sci. 9 (1958) 163-169.

704 [9] A.J. Lewry, J. Williamson, The Setting of Gypsum Plaster: Part II The development of 705 Microstructure and Strength, J. Mater. Sci. 29 (1994) 5524-5528.

706 [10] D.P. Bentz, S. Mizell, et al., The Visible Cement Data Set, J. Res. Natl. Inst. Stan. 107 (2002) 707 137-148.

708 [11] A. Bouterf, S. Roux, et al., Digital volume correlation applied to X-Ray tomography images 709 from spherical indentation tests on lightweight gypsum, Strain 50 (2014) 444-453.

710 [12] E, Gallucci, K. Scrivener, et al., 3D experimental investigation of the microstructure of cement 
711 pastes using synchrotron X-ray microtomography ( $\mu C T)$, Cement Concrete Res. 37 (2007) 360712368.

713 [13] J.Y. Buffiere, E. Maire, et al., In Situ Experiments with X ray Tomography: An Attractive Tool

714 for Experimental Mechanics, Exp. Mech. 50 (2010) 289-305.

715 [14] M. Abramoff, P. Magalhaes, et al., Image processing with ImageJ, J. Biophotonics Int. 11 716 (2004) 36-42.

717 [15] J. Schindelin, I. Arganda-Carreras, et al., Fiji: an open-source platform for biological-image 718 analysis, Nat. Methods 9 (2012) 676-682.

719 [16] E. Maire, P. Colombo, et al., Characterization of the morphology of cellular ceramics by 3D 720 image processing of X-Ray tomography, J. Eur. Ceram. Soc. 11 (2004) 36-42.

721 [17] S. Meille, M. Saadaoui, et al., Mechanisms of crack propagation in dry plaster, J. Eur. Ceram. 722 Soc. 23 (2003) 3015-3112.

723 [18] E. M. Gartner, Cohesion and expansion in polycrystalline solids formed by hydration reactions 724 - The case of gypsum plasters, Cement Concrete Res. 39 (2009) 289-295.

725 [19] S. Meille, E.J. Garboczi, Linear elastic properties of 2D and 3D models of porous materials 726 made from elongated objects, Model. Simul. Mater. Sc. 9 (2001) 371-390.

727 [20] G. Dumazer, V. Narayan, et al., Modeling Gypsum Crystallization on a Submicrometric Scale, 728 J. Phys. Chem. C 113 (2009) 1189-1195.

729 [21] A. Lemarchand, F. Boudoire, et al., Plaster Hydration at Different Plaster-to-Water Ratios: 730 Acoustic Emission and 3-Dimensional Submicrometric Simulations, J. Phys. Chem. C 116 (2012) $731 \quad 4671-4678$. 


\section{Figure Captions}

738 1. Microstructural changes during the setting of plaster. Reconstructed 2D slices extracted from the $7393 \mathrm{D}$ volumes acquired during the in-situ tomography experiments, between 800 and 3000 seconds.

740 The last slice (24h) was obtained after drying at $45^{\circ} \mathrm{C}$.

742 2. 3D rendering of a) $\mathrm{HH}$ particle (800 s), length $=123 \mu \mathrm{m} \mathrm{b}$ ) Resulting mesopore after setting and 743 drying $(24 \mathrm{~h})$, length $=113 \mu \mathrm{m}$.

3. Histograms of the gray values measured in the volumes for different times during setting and 746 then subsequent drying at $45^{\circ} \mathrm{C}$.

748 4. Evolution of the intensity of the HH peak (dashed line in Figure 3, gray level value $=0.31$ ) and of 749 the gypsum peak (dashed line in Figure 3, gray level value $=0.21$ ).

751 5. Gray values profile along the red line taken at different setting times. The measurement was 752 focused on a small HH particle (20 $\mu$ m thick).

754 6. Gray values profile along the red line taken at different setting times. The measurement was 755 focused on a large $\mathrm{HH}$ particle (70 $\mu \mathrm{m}$ thick).

7. a) $\mathrm{HH}$ thickness evolution during setting for different classes of initial particle sizes b)

758 Normalized thickness evolution of $\mathrm{HH}$ particles (solid lines). The dashed line corresponds to the 759 average $\mathrm{HH}$ dissolution throughout the whole volume as measured from data of Figure 4 (evolution 760 of normalized intensity of $\mathrm{HH}$ gray value peak). 
762 8. Reconstructed 2D slices extracted from 3D volumes of set plaster samples obtained with a) the 763 as-received $\mathrm{HH}$ powder and b) $\mathrm{HH}$ powder sieved below $40 \mu \mathrm{m}$ - voxel size of $2.5 \mu^{3}$ and set

764 plasters samples prepared with c) as-received powder and d) powder sieved below $40 \mu \mathrm{m}$ - voxel 765 size of $0.4 \mu^{3}$.

766

767 9. Size distribution of mesopores in set plaster for different HH granulometry. « Reference » for 768 sample prepared with as-received $\mathrm{HH}$ powder, « < $40 \mu \mathrm{m}$ » for $\mathrm{HH}$ sieved below $40 \mu \mathrm{m}$.

769

770 10. Granulometry of the porous «phase » (a) and of the gypsum phase (b) measured from high 771 resolution acquisitions $\left(0.4 \mu \mathrm{m}^{3}\right.$ voxel size).

772

773 11. Schematic representation of the hydration process as monitored by X-Ray tomographic 774 observation (blue : water ; black : entrapped air; white : HH particles of typical size between a 775 few $\mu \mathrm{m}$ and tens of $\mu \mathrm{m}$; gray : DH crystals).

778 Supplementary Online Materials

780 Video 1: time lapse movie of plaster setting 